\title{
Materialization of the Innovation Entrepreneurship Education Reform, Building of the Innovation-driven Talent Highland-Take Zhuhai College of Jilin University as an Example
}

\author{
Ming SUN ${ }^{1}$ and Ya-kun YANG ${ }^{2}$ \\ ${ }^{1}$ Zhuhai College of Jilin University, Zhuhai, China \\ ${ }^{2}$ Jilin University, Changchun, China \\ 15820581056@139.com
}

Keywords: Innovation entrepreneurship, Innovation-driven.

\begin{abstract}
Applied university should exercise its key role in talent development, scientific research, social service and so on, revolve around the materialization of the innovation entrepreneurship education reform, adopt the differentiation strategy that is different from research university, keep in synergic development with local economy and society, accelerate the establishment of the drive mechanism for source innovation, build the innovation-driven talent highland, and promote the local economic and social development. The author's university targets at the development of applied talents, orients at the materialization of the innovation entrepreneurship education reform, adheres to the total innovation, enables the unified and synergic development among scientific innovation, system innovation and open innovation, and exercises the positive effects of university in the innovation-driven strategy.
\end{abstract}

\section{Introduction}

\section{Seize the Opportunities of Innovation-driven Development}

University is the major force of talent development and the power station of scientific reform for a country or region, and the important forefront for the enhancement of cultural soft power. Throughout the development of history, university is treated as the key support in the implementation of innovation-driven development strategy, whichever the country or region is. The first university in Medieval Europe, University of Bologna, drove the ship of the Renaissance from Apennine peninsula and made science an edge tool for people to understand and transform this world; With two of the world's best universities - Oxford and Cambridge Britain began to lead the first industrial revolution; after the founding of Humboldt-Universität zu Berlin, the world technology center began the shift to Germany, making it the most important country during the second industrial revolution; when Americans incubated their modern universities by drawing upon the experience from German creation of research university and infusing these experience in the traditional liberal arts transplanted from British people, crowning it as the key players in the third industrial revolution.

After 30 years of fast-track development since the reform and opening up, China's economy has stepped in the key node of the extensive growth featuring quantitative expansion to the intensive development primarily depending on technological advance. In a positive response to the world new round of technological revolution and industrial transformation, 
higher education should even more honor its sense of social responsibility and historical mission, exercise its own advantages and characteristics, and make a difference in the implementation of innovation-driven development strategy. Moreover, applied university as the critical parts of higher education should even more seize the opportunities of innovation-driven development, and make its due contribution to the materialization of higher education reform and the local economic and social development.

\section{Play a Key Part of Applied University in the Innovation-driven Strategy}

As the innovation-driven strategy is locally implemented where the applied university is located, the fundamental purpose is to enhance the regional competitiveness, or the enhancement of regional adaptability to the process of social and economic structural transformation, which coincides with the goals of intensive growth pursued by applied university in that they should be globally considered under the context of "milieu innovateur". "Milieu innovateur" can be traced back to the viewpoint proposed by Groupe de Recherche Europen sur les Milieus Innovateurs"(GREMI). In the Barcelona Conference of 1989, GREMI defined a new spatial development theory model - "milieu innovateur", which can be defined as "a set". In other words, the informal relationship network mainly in a certain geographical area often determines a specific external image, special internal representation and the consciousness of belongingness, which fosters the regional innovation capacity through collaborative and common learning process[1]. The theory of "Milieu innovateur" states that environment is a must to innovation and the expertise, local connection and investment, market access and high-quality labor forces are the key factors which play a decisive role in regional innovation. The innovation-intensive business should partner with other businesses and work with training center, technology transfer center and local authority to tap various resources in the environment, jointly create the new localized production units, and create the favorable environment for innovation. In the setting of "milieu innovateur", university acts as the training center and technology transfer center, which coincides with the functions of modern university, "talent development, scientific research and serve society". Applied society as local institution should take the initiative to serve the local development, which is the objective demand of regional economic and social development and the essentials for its survival and development.

First, applied university should pay great attention to the organic integration of academic and professional nature, mainly develop the high-quality talents for the production forefront, follow the principle of "industry leads the subject, subject serves the industry and industry promotes the employment" with a view to the disciplinary planning and subject design, and tailor the talents that best suit the local and economic social development; second, applied university should innovate the mode of talents development, and cultivate the high-quality talents with innovative spirit and entrepreneurship consciousness for the local economic and social development. In the talent development program, applied university should increase the weight of practices, consolidate the "extracurricular education" and "professional skills training", and cooperate with businesses in collaborative talent development, according to the actual needs of industry and sector; last, local university can leverage its scientific resources and academic advantages, revolve around the local industrial development, technological innovation of businesses and upgrading of products for the rendering of technological service in the development of applied talents, and make the exploration and research of urban development serve the government decision-making. 
The innovation-driven development can be briefed as the men's creation, which means that innovation will be depleted and exhausted without talents. Talents are the foundation to innovation and the core of innovation, and the innovation drive is nothing but the talent drive. To implement the innovation-driven development strategy, a large scale, innovation-intensive and exploitative innovation team should be built as soon as possible, the local applied university should "attend to the demands of regional economic and social development, and develop a great many of high-level applied talents of endured will, retention and usability as a response to the demands of local economic construction and social development"[2]. The newly built applied university is evidently deficient in school-running condition, funds, teachers' qualification and quality of students and others. Only in the differentiated development route can applied universities maintain their competitive edge and enhance their core competitiveness. Exactly they should focus on the development of applied talents, equally treat the scientific research and social service before playing an active part in the implementation of innovation-driven strategy.

\section{Rely on Advanced Concept to DIrect the Innovation Entrepreneurship Education Reform}

The materialization of education reform of innovation and entrepreneurship is the major tool for applied university to boost the local innovation-driven strategy, the important approach to build the innovation-driven talent highland, while the innovation entrepreneurship education reform cannot be implemented without the clear awareness and understanding of core concept of the innovation entrepreneurship education.

1. Innovation entrepreneurship education is the new field of quality education

Innovation entrepreneurship education can be dated back to the period in 1989-1998, during which UNESCO raised the concept of enterprise education, or "entrepreneurship education and innovation fostering". Concretely, it means cultivating the individuals with innovation capacity, encouraging the spirit of adventure, enable people to master the innovation technology and demonstrate the ability of innovation and independent work, higher education should conduct entrepreneurship education training guidance, develop students' entrepreneurial skills and innovative spirit, and turn more and more graduates from the only identity of job seekers to the job creators[3]. The official paper titled Opinions of the Ministry of Education on Encouraging the Innovation Entrepreneurship Education and Undergraduate Entrepreneurship, issued on May 4th of 2010, is the first Chinese document that incorporate the innovation entrepreneurship education into the scope of higher education, and make it clear that "innovation entrepreneurship education is a teaching notion and mode created for the needs of economic, social and national development strategy[4]." After five years, General Office of the State Council issued an official paper titled Implementing Opinions on Materializing the Innovation Entrepreneurship Education Reform in Universities on May 4th of 2010, which marks the "innovation entrepreneurship education" elevated to the national strategy level, finally specifying the contents of "innovation entrepreneurship education" with Chinese characteristics; it focuses on the development of students' innovation spirit, entrepreneurship consciousness and innovation entrepreneurship capacity, emphasizes the practices, and conducts the education activities to stimulate students' creativity, so as to suit the needs of economic, social and national development strategy[5]. 
The connotation of "innovation entrepreneurship education" suggests that the quality of people can be described by "innovation spirit, entrepreneurship consciousness and innovation entrepreneurship capacity", and all education activities targeting at improving the quality of people can be collectively referred to as "quality education". This indicates some correlation between "innovation entrepreneurship education" and "quality education", which has been validated in the CCCPC Decision on Deepening the Education Reform and Comprehensively Promoting the Quality Education issued in 1999. This paper states "higher education should emphasize the fostering of undergraduates' innovation, practice ability and entrepreneurship spirit, and improve their humanistic and scientific quality." Innovation entrepreneurship education "extends the intension and extension of knowledge domain, breaks through the restraint of university mainly imparting "the traditional and modern explicit knowledge which enables the systematic processing by languages and graphics", treat the accumulated human experience, lesson and other implicit knowledge which activate the students' innovation spirit and entrepreneurship consciousness, as the deepening reform of knowledge area" in the process of developing undergraduates" "innovation spirit, entrepreneurship consciousness and innovation entrepreneurship capacity"[6]. Innovation entrepreneurship education is the deepening and materialization process of quality education in the new era and the new field of quality education.

2. Innovation entrepreneurship education is oriented at the potential development

The primary goal of the innovation entrepreneurship education reform is to "guide the higher education institutions to renew the education concept, reform the talent development mode, education content and teaching method, couple talent development, scientific research and social service, transform from knowledge transfer to more emphasis in fostering ability and quality, and improve the quality of talent development[7]." This coincides with the focus of quality education on the development of self-study and self-development ability and the potential harnessing of the educated, and the goal of promoting the all-around development morally, intellectually and physically, which can be briefed as harnessing people's potentials, arousing the hidden desire and set free the gift. Thus, innovation entrepreneurship education should also follow the concept of potential development of quality education, break away with the traditional education mode of knowledge transfer, focus on the harnessing of students' potential in innovation and entrepreneurship and promote the all-around development of people from the perspective of sustainable development.

People's ability takes in two forms, one is the external and actual ability; the other is the potential form, or the ability leashed due to various factors, i.e.: "potential". Generally, potential has the features of universality, hiding, differentiation and exploitability. The exploitation of one's potential means exploiting the energy composed of stamina and intelligence hidden in human body, make it exercise to the utmost. With a view to the exploitation of innovation entrepreneurship potential, it requires the university to establish the innovation entrepreneurship education system through a package of reforms in accordance with its orientation of talent development. To implement the innovation entrepreneurship education reform, applied university must highlight the systematic development of ability, emphasize on the application and skill-based nature, students' comprehensive professional theoretical base and good cultural quality and elementary education and sustainable development ability. Thus, knowledge, ability, responsibility and spirit should be organically coupled in the development process of innovation and entrepreneurship of applied talents. In which, the development of overall quality should highlight the education mission of morality and integrity; the development 
of occupational skills and practical ability should be throughout the process of specialized education; based on the stimulation of students' personality characteristics, their subjective initiative for the exploration of the unknown world and bold practices should be fostered, developing their innovation spirit; everyone has own potential, entrepreneur's thinking belongs to divergent thinking or individualized thinking, the unified education concept and standardized teaching mode has limited effects on the stimulation of students' potential, so the innovation entrepreneurship education should even more adhere to the principle of individualized teaching.

3. Pay full respect to the subject position of students and play the leading role of teachers

Innovation entrepreneurship education needs to follow the rules of education, in which the most fundamental and important part is to pay full respect to the subject position of students and play the leading role of teachers. Marxism epistemology believes that cognition is the active reflection of the subject to the object. Teaching cognition is a special activity whose particularity is mainly shown in the students' individual cognition under the leadership of teacher, the cognition primarily in the form of indirect experience and the cognition of development value and regarding the development as mission [8]. Teaching cognition includes a great variety of teacher-students interactions, students as the subject is the internal cause of cognition activity. While teacher is the external cause, he can become the leading force of students' development under certain circumstance, and play the decisive role.

In the process of innovation entrepreneurship education reform conducted by applied university, the subject position of students is reflected in the education activities in strict alignment with the requirements for the quality development of innovation and entrepreneurship. To put it another way, students should be given a referential quality standard while teaching activity should be given a quantitative model. According to the China's relevant guidance on innovation entrepreneurship education and the features of talent development in applied university, innovation entrepreneurship talents should be composed of the following basic quality elements: 1 . The knowledge system consisting of professional expertise, market economy knowledge, social knowledge and scientific research methodology; 2. The innovation entrepreneurship ability including entrepreneurship spirit, responsibility awareness, development motive(entrepreneurship awareness) and the spirit of perseverance; 3 . The innovation entrepreneurship ability including decision-making ability, organizational ability, teamwork ability and interpersonal skills that constitutes the innovation and entrepreneurship talent quality model. The objectives and results of innovation entrepreneurship education can be comprehensively assessed by constructing the innovation and entrepreneurship talent quality model. Further, the individualized teaching is enabled by classifying the students' innovation entrepreneurship ability according to the differentiation created from different variable elements.

An innovation-based faculty must be built to exercise the leading role of teachers in the innovation entrepreneurship education to the utmost. The main actions include focusing on the job training and improving teachers' innovative teaching ability; strengthening industry-teaching-research cooperation, and enhancing teachers' innovative research ability; emphasizing the team building, and promoting the overall enhancement of the faculty's innovative ability; creating the institutional environment, and providing guarantee for the innovative faculty building. In addition, based on the high relevance between innovation entrepreneurship activity and social economic activity, applied university should facilitate the school-business cooperation, and build a double-professionally-titled faculty mainly made up 
of engineering technicians and business managers; applied university should reinforce the talent flow mechanism of in-campus and off-campus teachers, so as to make the full-time teachers understand the real problems in workplace and let part-time teachers bring the cutting-edge business and industry technologies and managements to the classroom; "entrepreneurship mentor" should be introduced to the practical teaching of innovation and entrepreneurship, designating those teachers with convertible scientific result, managerial experience, enthusiasm and responsibility as entrepreneurship mentors, so as to guide students in the innovation and entrepreneurship practices.

\section{Exploitation and Practice of Innovation Entrepreneurship Education Reform in Zhuhai College of Jilin University}

ZhuhaiCollege of Jilin University (hereinafter referred to as "school") is a local undergraduate college with relatively short history. Since the establishment, it has precisely oriented according to the realities, committed the construction of applied university, adhering to the notion of "serve to seek support, contribute to promote development", revolving around the actual needs of Zhuhai and Guangdong social and economic development, it actively seeks the coherence point between its own strengths and local social and economic development, endeavors to collaborate with the innovation and entrepreneurship activity infusing the innovation-driven strategy through talent development, scientific research and social service, enables the unified and synergic development among scientific innovation, system innovation and open innovation, and exercises the special effects of university in the innovation-driven strategy, creating its own school-running with local characteristics. On May 13 of 2015, it was listed as the Guangdong model school for innovation entrepreneurship education.

1. Build the innovation-based faculty, drive the technological innovation and social service level

The school grips the economic and social development trend in the Pearl River Delta and Zhuhai's demands for "high-end manufacturing industry, hi-tech technology industry, high-end tertiary industry and special marine economy and ecological agriculture" industrial structure, encourages, supports and fosters teachers to actively create conditions, strive for scientific research project, and participate in scientific research works while ensuring the quality of teaching assignments. In 2014, the school began to launch the "three-level" key faculty building program, in great endeavor to build a key faculty made up of the young and middle-aged subject (academic) leaders, key teachers and teaching and research-oriented teachers. By now, this faculty has become the major force of the innovation entrepreneurship education reform and is awarded 1 subproject under "The Twelfth Five-year Plan" National Major key S\&T Special Projects, 4 projects under National Science Foundation, 2 projects under Guangdong Provincial Natural Science Foundation, 1 project under Ministry of Education Social Science Foundation, and 13 other provincial projects; also awarded 1 project of the 16th National Excellent Social Science Popular Works. In October of 2014, 24 teachers were elected the eighth candidates for the higher education "1000, 100, 10 Talents Development Program", ranking the first place among 51 private universities in terms of elected number, in June of 2015, 4 teachers were listed in the financially supported distinguished scholars of Zhuhai, each of them has an access to RMB 10 financial support from Zhuhai Municipal Government, which marks its remarkable accomplishments in building the faculty of innovation-based teachers. 
The school integrates the scientific strength resources, builds a series of public service platforms, in which the biomedical public service platform is the often-cited example. Now this platform is known as "Zhuhai Municipal Biomedicine Public Service Platform" and "Guangdong Public Service Demonstration Platform for Provincial Small and Medium-sized Enterprises", with 2 national distinguished experts under "Thousand Talents Program", 1 national "Ten Thousand Famous Teachers Program", 2 distinguished professors under the Ministry of Education "Changjiang Scholars", 1 national new medicine evaluation committee, 1 Guangdong provincial leading scholar, 9 doctoral supervisors and 16 master supervisors. Until now, this platform has undertaken 15 provincial-level scientific research projects, with total scientific funds of RMB 4.479 million, 60 more publications, in which 33 are SCI high-level academic papers. Two international biomedicine academic conferences and industrial docking were held in 2013 and 2014 respectively, which attracted biomedicine experts and scholars and hundreds of famous pharmaceutical enterprises from home and abroad, promoted the academic exchange and industry-teaching-research cooperation in pharmaceutical sector and signed several scientific projects. In 2015, "Biomedicine Collaborative Innovation Center" based on the biomedicine public service platform was approved as Zhuhai Municipal Collaborative Innovation Center Project, with an approved funds of RMB 3 million.

The improvement of teachers' scientific research ability and the construction of scientific research service platform strongly promote the enhancement of talent development level. In 2013, the school signed the cooperative agreement for postgraduate development with Graduate School of Jilin University. Relying on Nanfang Graduate School of Jinlin University, the school enrolls and develops the professional degree postgraduates in the whole process for seven subjects: Finance, mechanical engineering, electronics and communication engineering, chemical engineering, pharmaceutical engineering, biological engineering and computer technology, which underpins its independent application for master degrees awarding units.

2. Deepen the mechanism system reform by means of institutional innovation, build the innovation-oriented talent development system

The school builds the innovation entrepreneurship education leading group where the secretary of Party Committee and the dean act as the leader, enhances the top-level design, arranges the innovation entrepreneurship education reform, vigorously promotes the school-running in accordance with law, establishes the institutional system in the core of school regulations and provides the developed system guarantee for the innovation entrepreneurship education reform. Besides, it also adjusts the structure of academic institutions, makes clear the key status of Academic Committee in discipline construction, subject construction and faculty building in academic affairs, sets up five discipline subcommittees (Arts and Humanities Discipline Subcommittee, Economic Management Discipline Subcommittee, Information Discipline Subcommittee, Mechanics Discipline Subcommittee, Chemistry and Medicine Discipline Subcommittee), and highlights the academic leading role of disciplines in the innovation entrepreneurship education reform.

The school vigorously constructs the teaching system for the innovation-based talent development, keeps reforming the talent development program, course system, teaching mode and teaching method, emphasizes the practical teaching, strengthens the skill training, closely associates the professional knowledge and relevant sectors and industries, actively conduct the "order-based" teaching tailored for the businesses and industries, encourages the microteaching and interest-oriented and individualized development. The school organizes 
several revisions and additions to the Undergraduate Talent Development Program of 2013, and docks it with talent development objective and orientation. After such revision, the weight of practices in total credits is increased, in which the weight of liberal arts, science and engineering practices in total credits is $25 \%, 32 \%$ higher; it strengthens the implementation and management of "extracurricular development program" and "professional skills practical training", and formulates the action plan. The new talent development program highlights the strengths of professional talent development, Department of Tourist Management, for an example, relies on the quality tourist culture resources in the Pearl River Delta, and finds an opportunity in Zhuhai's vigorous development of high-end tertiary industry, which leads to the optimization of the professional structure and the innovation of the talent development mode. Of which, Hot Spring Management is working with Zhuhai Yu Hot Spring Tourist Resort on the formulation of national standard for the hot spring tourist industry China Evaluation Norm for Hot Spring Resources; Hotel Management signs the cooperation agreement with Zhuhai Huafa Group to run "Huafa - Sheraton Talent Order Class", synchronizes the teaching and practices, and infuses the internship with employment. Thanks to their efforts, these students have developed to be the cornerstone of Zhuhai tourist culture brand.

Revolving around the objective of talent development, the school actively adjusts the course program, adds the contents of entrepreneurial guidance, constructs the course system made up of elementary theory curriculum, practical application curriculum, and comprehensive quality extension curriculum, particularly highlights the development of students' practical ability, and increases the practical course hours and credits. Coupling with Guangdong Provincial "Cooperative Education Program", it facilitates the implementation and management of "extracurricular development program" and "professional skills training", and strengthens the development and training of innovation entrepreneurship education. The compulsory credits for the innovation entrepreneurship education and "innovation entrepreneurship" must be no less than 8,4 credits respectively, and it sets forth the implementation program. Department of Chemistry and Pharmacy coordinates the regional social power to conduct the " 351 " practical teaching system construction. (" 3 " means integrating three practical teaching modules: elementary experimental teaching module, professional practice module, internship and production comprehensive operation module; "5" means five practice levels: elementary, professional, practical, production internship and graduation design; " 1 " means the internship practices throughout the practical teaching), through deepening the cooperation with the Zhuhai-based BY-HEALTH, UNITED LABORATORIES and other large-sized enterprises, it establishes the "three-in-one" practical teaching sharing platform that integrates basic experimental technology training, simulative production process training and production, and research technology internship by means of applied technology, guides students to get trained from the basic technology and approach, conduct the elevated live training and the innovation-based scientific research training, facilitating the students' innovation entrepreneurship skills.

3. Drive the construction of collaborative innovation centers, collaborative cultivation platforms and entrepreneurship incubators by means of open innovation

The school runs with the opening attitude, deepens the all-around cooperation of government, industry, teaching, research and fund, focuses on the development of three school-level collaborative innovation centers ("Biomedicine Collaborative Innovation Center", "Internet and Intelligent Information Processing Collaborative Innovation Center", "Machinery and Equipment Design and Manufacturing Collaborative Innovation Center") and two 
collaborative cultivation platforms ('Electronics Information Collaborative Cultivation Platform", "Economic Management Collaborative Cultivation Platform"). Of which, Biomedicine Collaborative Innovation Center is initiated by Department of Chemistry and Pharmacy, made up of 11 collaborative units including three universities (College of Life Sciences of Jilin University, Zhuhai College of Jilin University, Beijing Institute of Technology, Zhuhai), two research units (Zhuhai Baode Runsheng Health Technology Co., Ltd, Zhuhai Jinzhidun Biomedical Science Co., Ltd) and six new hi-tech technology enterprises (Zhuhai Ansheng Fenghuang Pharmaceuticals Co. Ltd, Zhuhai Lizhu McAb Biotech Co., Ltd, Zhuhai United Laboratories Co., Ltd, Zhuhai Rundu Pharmaceuticals Co. Ltd, Zhuhai Jinhong Pharmaceuticals Co. Ltd, Macau Central Pharmaceuticals Co. Ltd), who collectively endeavor to enhance the development capacity for the scientific research ability and top innovation talent, serve and lead the transformation and upgrading of pharmaceutical industry. Biomedicine Collaborative Innovation Center worked with Zhuhai Ansheng Fenghuang Pharmaceuticals Co. Ltd on the "technology upgrading research for the secondary development of Huoxue Zhitong Capsules", increasing the product efficacy and safety and enhancing the market competitiveness. It is estimated that: 1 billion pills can be sold after the second development of Huoxue Zhitong Capsules, the annual profits will be RMB 300 million, in which the YOY tax and profit increase will be RMB 40 million. The collaborative cultivation platform of electronics information talents jointly established by Department of Electronic Information and Computer Science and relevant enterprises was awarded the Second Prize of the 7th Guangdong Provincial Education Teaching Achievements for its talent development model in June 2014; the students out of this platform have obtained 28 national-level prizes, 3 special prizes and 5 first prizes from the national contests, such as National Undergraduate Electronic Design Contest and ACM International Collegiate Programming Contest (ACM).

The school invests more than RMB 2 million to establish the Undergraduates Entrepreneurship Incubator with an area of more than 1,000 m2, endeavors to make students seek knowledge from practices and transform themselves from passive acceptance to active exploration. 35 persons (all are the heads of small and micro businesses in the incubator) received trained in the first term through lecturing the entrepreneurship practices and aroused students' entrepreneurship spirit; launched the 'Entrepreneurship Nursery Program”, held 12 entrepreneurship salons, attended by 1,500 students, held two investment and financing road shows, attended by 12 businesses; built the "three talks" entrepreneurship salon brand, "school leaders talk about entrepreneurship, outstanding entrepreneurs talk about entrepreneurship, excellent alumni entrepreneurs talk about entrepreneurship", boosts the confidence of entrepreneurship students, and offers the intellectual support in an effective and timely manner for any student intended to start a business. The atmosphere of innovation entrepreneurship is also unconsciously intensified through the irregular public day of Undergraduate Entrepreneurship Incubator, Press Conference of Entrepreneurs from Zhuhai College of Jilin University, the first session of Wechat Business Forum of Zhuhai College of Jilin University and other self-operated brand activities held by incubator businesses. Dean's office and Entrepreneurship Incubator launched 80 projects under the Undergraduate Innovation Entrepreneurship Training Program, applied 50 projects under the Guangdong Provincial Innovation Entrepreneurship Training Program, and worked with Zhuhai municipal and Jinwan District government to establish the service system that integrates "project selection-project incubation-project support-project delivery". To date, the number of businesses based in incubator is 23 , in which 5 are successfully incubated, the sales revenue amounts to more than 
RMB 1.5 million, with profits of more than RMB 0.5 million, of which Zhuhai Youth Media Co., Ltd received the strategic investment of RMB 1.5 million in June 2015. In the recent National Final of China "Internet+" Undergraduate Innovation Entrepreneurship Contest, the delegation of Zhuhai Youth Media Co., Ltd and Zhuhai Cloud Cubic Logistics Co., Ltd which are based in incubator was awarded the Practices Bronze Medal.

\section{References}

[1] Li Yuan. Innovation environment and the starting point of its policies - A discussion of the enhancement of the regional globalization competitiveness. [J] Economic Geography, 1999(19)

[2] Zhu Kerong. The core competitiveness and facilitating strategy for applied university. [J]Journal of Beijing Union University (Humanities and Social Sciences), 2006(04).

[3] Sun Ming, Yang Yakun. Materializing the innovation entrepreneurship education of applied university by means of advanced concept. Pearl River Forum[J], 2015(3)

[4] Opinions of the Ministry of Education on Encouraging the Innovation Entrepreneurship Education and Undergraduate Entrepreneurship[Z], 2010.05.05

[5] Zhang Bing, Bai Hua. A discussion on the concept of "university innovation entrepreneurship education'[J]. Higher Education Exploration

[6] Zhang Bing, Bai Hua. A discussion on the concept of "university innovation entrepreneurship education'[J]. Higher Education Exploration 2014(3)

[7] Shi Guoliang. Undergraduate innovation entrepreneurship education in the time context[J]. Journal of Research on Ideological Education, 2010(10)

[8] Liu Jiping. "Teacher plays the leading role, students are in the subjective position": A demonstration on the justification of a classical formula[J]. Journal of Beijing Normal University(Social Sciences) 2015(4) 